\title{
Living in a bottle: Bacteria from sediment-associated Mediterranean waste and potential growth on polyethylene terephthalate (PET)
}

\author{
Àngela Vidal-Verdú ${ }^{1}$, Adriel Latorre-Pérez ${ }^{2}$, Esther Molina-Menor ${ }^{3}$, Joaquin Baixeras ${ }^{4}$, \\ Juli Peretón ${ }^{3}$, and Manuel Porcar ${ }^{3}$ \\ ${ }^{1}$ University of Valencia \\ ${ }^{2}$ Darwin Bioprospecting Excellence SL \\ ${ }^{3}$ Institute for Integrative Systems Biology \\ ${ }^{4}$ University of Valencia Cavanilles Institute of Biodiversity and Evolutionary Biology
}

December 17, 2021

\begin{abstract}
Ocean pollution is a worldwide environmental challenge that could be partially tackled through microbial applications. To shed light on the diversity and applications of the bacterial communities that inhabit the sediments trapped in artificial containers, we analyzed residues (Polyethylene terephthalate (PET) bottles and aluminum cans) collected from the Mediterranean Sea by scanning electron microscopy and Next Generation Sequencing. Moreover, we set a collection of culturable bacteria from the plastisphere that were screened for their ability to use PET as a carbon source. Our results reveal that Proteobacteria are the predominant phylum in all the samples and that Rhodobacteraceae, Woeseia, Actinomarinales, or Vibrio are also abundant in these residues. Moreover, we identified marine isolates with enhanced growth in the presence of PET: Aquimarina intermedia, Citricoccus spp., and Micrococcus spp. Our results suggest that the marine environment is a source of biotechnologically promising bacterial isolates that may use PET or PET additives as carbon sources.
\end{abstract}

\section{Hosted file}

MB032021090460.pdf available at https://authorea.com/users/451630/articles/549854-1iving-ina-bottle-bacteria-from-sediment-associated-mediterranean-waste-and-potential-growth-onpolyethylene-terephthalate-pet 